\title{
A hybrid learning pedagogy for surmounting the challenges of the COVID-19 pandemic in the performing arts education
}

\author{
Qingyun $\mathrm{Li}^{1} \cdot \mathrm{Zihao}_{\mathrm{Li}}{ }^{2} \oplus \cdot \mathrm{Jie} \mathrm{Han}^{3}$
}

Received: 1 December 2020 / Accepted: 26 May 2021 / Published online: 28 June 2021

(c) The Author(s), under exclusive licence to Springer Science+Business Media, LLC, part of Springer Nature 2021

\begin{abstract}
For performing arts education, Sage on the stage and Learn from the Masters were halted by the COVID-19 pandemic, and so did everything else. All lectures, tutorials and other face-to-face skill-based training sections were cancelled and were replaced by the online model. Such a model was only seen as one of the supplementary components for performing arts education in the past. From January 2020, this online pedagogy was inevitably placed to surmount the challenges caused by the COVID19 pandemic. The social distancing measures demanded the blended pedagogy into a new online approach, in which the traditional face-to-face teaching to be replaced by synchronous online learning (facilitated by technologies such as Zoom, Cisco Webex, Google Class, Panopto etc.). Meanwhile, to offer opportunities for cognitive participation which allows students to process the learning and be reflective, webinar and innovative performance projects were launched from the concept of 'flipped classroom and outcome-based education.' This mixed approach (blended learning, flipped classroom, and outcome-based education) is described as 'hybrid learning' in this study.

The 'hybrid learning' pedagogy is implemented at the Hong Kong Academy for Performing Arts (HKAPA) for all teaching activities in the 2nd semester 2020/2021 to overcome the challenges caused by the COVID-19 pandemic. A questionnaire survey about how it affected the performing arts education, and how the new pedagogy was implemented took place in July 2020. The survey results from both the teachers (76) and students (163) share lessons, insights, and new understandings on teaching and learning online. Hybrid learning has been widely investigated and researched, yet study on hybrid learning in performing arts such as creative art, theatre art and music, remains insufficient. This study fills the research gap.
\end{abstract}

Zihao Li

michaelli@hkapa.edu

Extended author information available on the last page of the article 
Keywords Performing arts education · COVID-19 pandemic $\cdot$ Hybrid learning · Synchronous online learning · Questionnaire survey

\section{Introduction}

For centuries, performing arts educators perceive pedagogy as a one-dimensional approach. Sage on the stage or follow the master used to be the 'only way' of teaching and learning. Theatre arts dramatists practice monologues while fine tuning facial expressions to match the director's desires. The process is so intense that many participants constantly hold their breath to make sure that certain emotions are correctly delivered. Dance and music students rely heavily on observations-gazing their eyes on their teachers' movements and play-demonstrations closely. After seeing, students repeat what their teachers have done, and they practice diligently. Their physical demonstrations are instantly critiqued by their teachers. It seems that there is little use of technology in these classes. That explains why dance, in particular, is one of the last subjects to embrace technology applications (Calvert et al., 2005). Theatre Entertainment Arts (TEA) teachers design costumes, build props, draw curtains, and test special lighting effects right in front of students, who watch attentively while noting down key concepts. Chinese Opera, one of the oldest forms of performing arts, would involve not only teachers but having legendary artists in the studio to pass the tradition (lecture) - a way to preserve the heritage and authenticity (Leung \& Leung, 2017). Even in the newer form such as Film and TV, professors would spend a long-time lecturing theory and introducing techniques such as Montage, Dolly, and Zoom. Nonetheless, the COVID-19 pandemic effectively cancelled all face-to-face classes, rehearsals, live performances, yet the show must go on. The social distancing measures forced everyone in performing arts to embrace the unfamiliar pedagogy, in which the traditional face-to-face teaching to be replaced by synchronous online learning. Everything goes online. Researchers in this study consider this Hybrid Learning, in a way, embarks a new stage for performing arts education.

Graham (2004) states that blended learning is a combination of face-to-face instruction and online learning. Traditional face-to-face teaching involves the interaction between students and teachers, while online learning facilitates the teaching and learning by using conventional or online methods without face-to-face contact between students and teachers. Students have been using spare time to learn the performing arts and, where possible, meet their teachers in person sporadically under extreme restrictions.

From January 2020, with the COVID-19 pandemic sweeping across the globe, the performing arts education and our daily lives have changed unexpectedly, and the situation has deteriorated quickly. It is a big challenge for our daily routines and negatively impacts the education. This situation demands the quick changes, from the traditional method of teaching to blended pedagogy merely depending on online teaching and learning is not ideal. The institution in this study combines synchronous learning, webinar and innovative performance projects (from the concept of 'flipped classroom and outcome-based education') to optimize teaching and learning 
experiences. In this study, researchers describe this mixed approach (blended learning, flipped classroom, and outcome-based education) as 'hybrid learning.'

Hong Kong Academy for Performing Arts (HKAPA), where this study takes place, is a leading tertiary institution in performing arts. It is ranked the world's no.10 and Asia's no.1 by the QS Ranking, in the Performing Arts category in 2021 (QS, 2021). The Academy focuses on promoting excellence in education in the performing arts, film and television, and theatre technical arts. It aims to nurture an outstanding generation of artists for the future and make a valuable contribution to the cultural life and development of Hong Kong. HKAPA has approximately 1,000 students and 140 teaching staff. The Academy offers academic programmes from diploma/foundation to master's degree level in six faculties: School of Chinese Opera (CO); School of Dance (DA); School of Drama (DR); School of Film and Television (FTV); School of Music (MU); School of Theatre and Entertainment Arts (TEA).

To prevent the spread of the COVID-19 through social contact, and with the continued concerns for the health and safety of teachers, students, and the general public, the campus is closed from January 2020 to August 2020 and courses are delivered via online model. The 'hybrid learning' therefore, is proposed to be used to surmount the challenges caused by the COVID-19 pandemic.

To know how the new pedagogy has helped teachers' teaching and students' learning, and how to further improve the learning experience during the temporary closure of the Academy, a questionnaire survey is conducted with teachers and students at the end of the semester (July 2020). 162 students and 76 teachers from different schools and departments participated in the survey. The survey results from both the teachers and students show the great success of the hybrid learning pedagogy.

This study recapitulates recent research in blended learning in section two, and describes the methodology of the mixed approach in section three. The questionnaire survey, result and findings are described in section four. The contribution of this study is concluded in section five.

\section{Literature review}

Blended learning is a combination of online learning and face-to-face learning, where flipped classroom learning reversed the delivery method in traditional learning. Traditional learning is a teacher-centred approach providing passive learning merely achieved a low level of thinking skill; whereas flipped classroom learning is a student-centred approach providing student engagement and active learning, emphasizing on engaging learners to structure their learning. In the past decade, the assistance of technology has enhanced academic performance, deepened learning and raised satisfactory level among involved students. Kassab et al. (2019) summarizes the existing merits and challenges on incorporating Internet of things in education, categorizing into three-dimensional scheme related to education mode, perception, and learning principle. The authors suggest more attention should be 
drawn on security issues, scalability of solutions, and humanization of the delivery system to improve the outcomes. The academic learning via blended learning has been widely investigated, but study on performing arts, such as creative art, theatre art and music, remains insufficient.

Implementation of mobile learning (m-learning) in theatre art may achieve simultaneous and exploratory environment, providing flexibility and efficiency to experience learning in terms of time and location, which offer opportunities to engage and utilize expertise without burdens such travel cost in the works of Crawford (2016), Li et al. (2018), Zhou and Li (2019) and Li (2020). For example, the online environment provides space for dissertation supervision, pastoral support and performance feedback in performing arts (Peacock et al., 2012). However, a limited wellorganised learning management system (LMS) integrating mobile technology and blended learning hampers the outcomes is proposed by Zhou and Li (2019). Although technology benefits education, access and expertise are associated to socioeconomic status in the works of Anderson (2012).

Similar problems are also suggested when technology is implemented in creative art. For instance, lack of flexibility in relation to navigation and interface, time consuming resources development, competence of tutors in technological aided educating tools and factors affecting the engagement of 'digital residents' is mentioned by Power and Kannara (2016). Some performing arts mainly rely on one-to-one teaching basis and real-time interaction, the conduciveness or necessary for blended learning may be limited because of additional burden on time for preparation, reported by Colombi and Knosp (2017), Power and Kannara (2016) and Li (2020). In contrast, Ruokonen and Ruismäki (2016) state that blended learning provides music students more opportunities for independency and active learning. Colombi and Knosp (2017) assert some theoretically materials and references can be provided to students before or after class, reserving time for selecting and listening to specific music during the face-to-face class for interactive activities. Nevertheless, the authors claim some visual components, such as showing a profile photograph, are able to establish a sense of belonging in real time teaching. Four factors, external environment, technology, curriculum and students from the work of Power and Kannara (2016), are also accounted to develop a practice model for virtual learning environment (VLE) implemented in creative art, demonstrating effective navigation and aesthetics improvement.

Ruokonen and Ruismäki (2016) have implemented a blended learning method in music via rotation method, providing a schedule of independent online study sessions in an e-learning environment and face-to-face classroom time for students. The learning process is divided into several phases, including plan, implementation, and evaluation, according to Amabile (1983)'s 'componential model of individuals or small groups' creative process. Colombi and Knosp (2017) use Note Bowl, one of the online course management systems (CMSs), to fulfil the expanding educational needs in dance as well as various learning styles among students. They conclude that online learning is improving in terms of increased interaction and capacity and it supports dance teaching. For instance, after showcasing learning materials synchronously or asynchronously, such as an audition, exemplar performance recordings, the students are required to discuss and write a report instead of simply providing 
a verbal report to boost learning engagement. Further, Ostashewski et al. (2016) and Li et al. (2018) suggest that portable devices, such as iPad and mobile phones provide a live demonstration in small groups. The use of these devices increases learning engagement between students via student-controlled playback and practice activities for review and interaction. It also benefits teaching in large groups outside traditional classroom.

Blended learning has been well researched. Draper and Hitchcock (2008) has proposed a 4-year-project reported back in 2008, indicating the majority of involved students utilized the Mutech Discussion Board (MDB), a blended learning instrument. It provides instant communication with the music technology, which supports music teaching as well as innovative pedagogy development. The shifting of music activities from cassettes or CDs to YouTube has also been observed, indicating the mode of music consumption, creation and distribution is affected, reported by Cayari (2011). Ruthmann and Hebert (2012) have discovered that the application of blended learning in music learning via online platforms or social media has shared the similar idea of providing more opportunities during the music study, as well as reinforcing the knowledge taught in-class and connection between musicians. Moreover, the authors emphasize the importance of students' engagement since the tools and the media desired and required may not be consistent among all the classes. That inconsistency leads to a difficulty to cover full course materials in-class within a limited time. By providing supplementary materials online, this problem could be rectified. Crawford (2016) has evaluated the implication of Web 2.0 platforms, which include social networking and various online multimedia such as Skype and YouTube, implemented in blended learning as high-quality learning resources of music by using a combination of Google Analytics and a tracking programme, demonstrating the interest and engagement of students to learn music, as well as the skills and confidence levels of the teachers using blended learning. Given that the learning analytics (LA) are used for data collecting, the learning behaviours rely on online learning can be investigated. Montgomery et al. (2019) report that self-regulated learning (SRL) behaviours, such as online duration, frequency, and learning patterns, in music education are associated with academic achievement. Data on how students have regulated their learning in certain measures, however, is not available due to limited research.

Referring to the previous studies, especially the works of Draper and Hitchcock (2008), Crawford (2016) and Ostashewski et al. (2016), performing arts educators must adopt a new pedagogy. It takes advantage of traditional blended learning and combine additional innovative approaches to enrich teaching and learning experiences to mitigate the negative impact caused by the COVID-19 pandemic.

\section{Methodology}

Ruthmann and Hebert (2012), Draper and Hitchcock (2008), Crawford (2016), Ostashewski et al. (2016) and $\mathrm{Li}$ et al. (2018) point out that hybrid learning for the students in learning performance arts is lacking promising evidence due to insufficient equipment, practice, and case studies. The new 'hybrid learning' pedagogy integrates the synchronous 


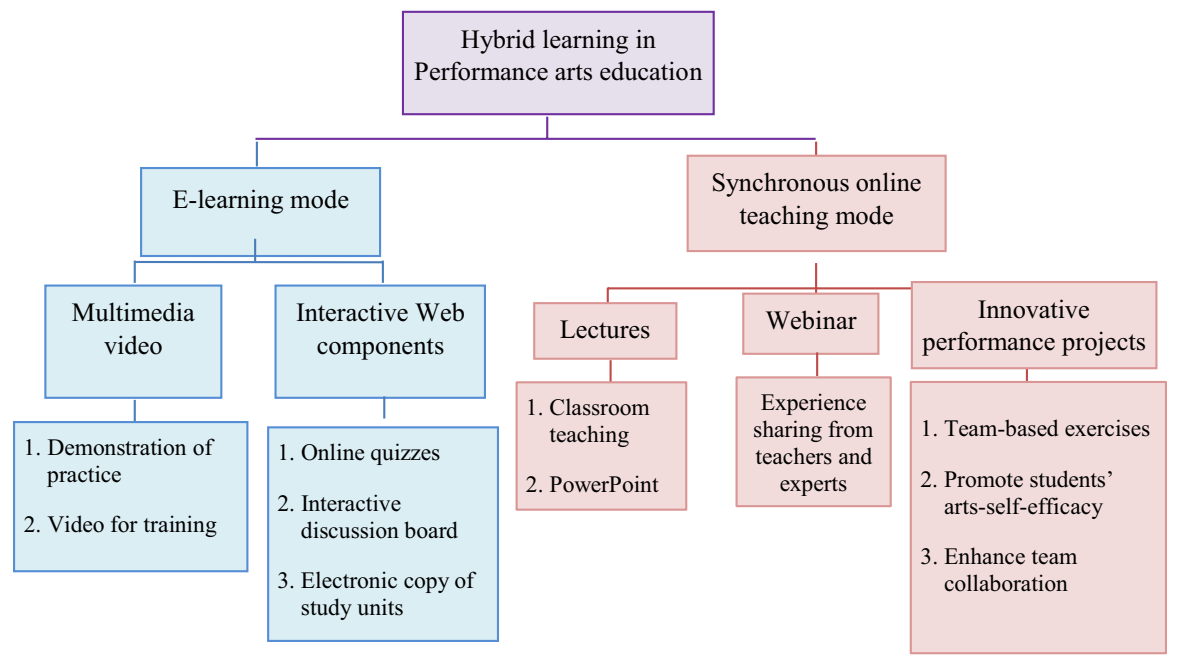

Fig. 1 Framework of the Hybrid learning in Performance arts education

online learning (facilitated by technologies such as Zoom, Cisco Webex, Google Class, Panopto etc.) and traditional lectures, regular webinars, innovative performance projects, and traditional e-learning, for student self-regulated learning to engage students in the active learning environment. It is an inclusive approach, and it provides valuable data to fill the research gap.

In this pedagogy, students can learn at anytime and anywhere from online classes, webinar, e-learning materials, and co-operate/practice with other students. Since these concepts and methods are mixed, 'hybrid learning' is used to describe this new approach in performance arts education. It integrates the features of online e-learning and synchronous online learning modes, together with the demonstration of professional training and practice in videos, podcast, and texts. More interactive

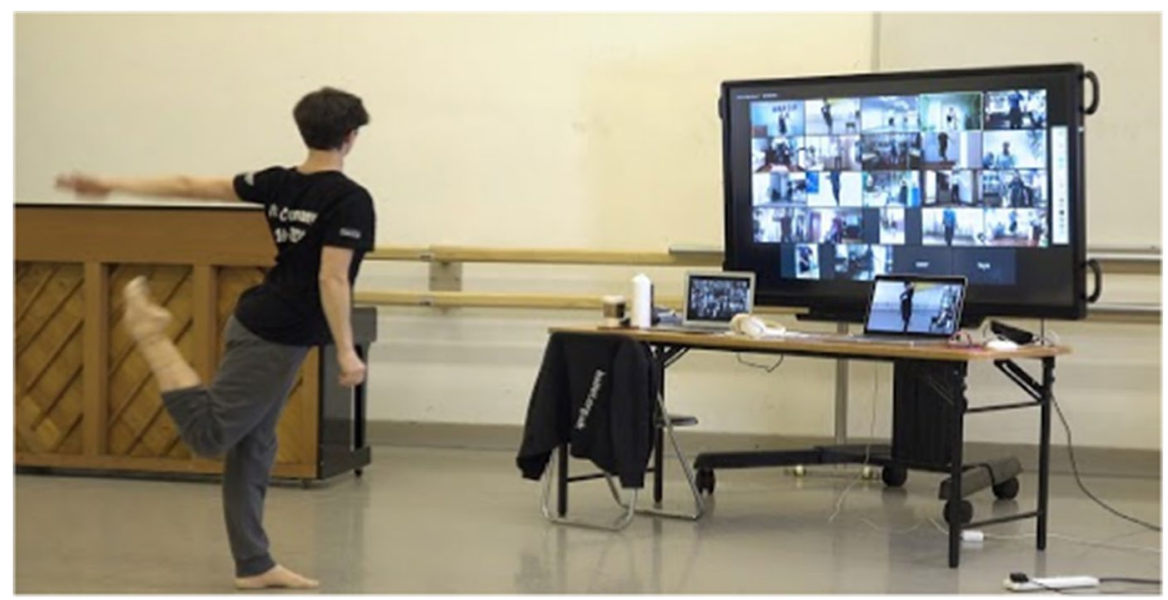

Fig. 2 A synchronous dance class 


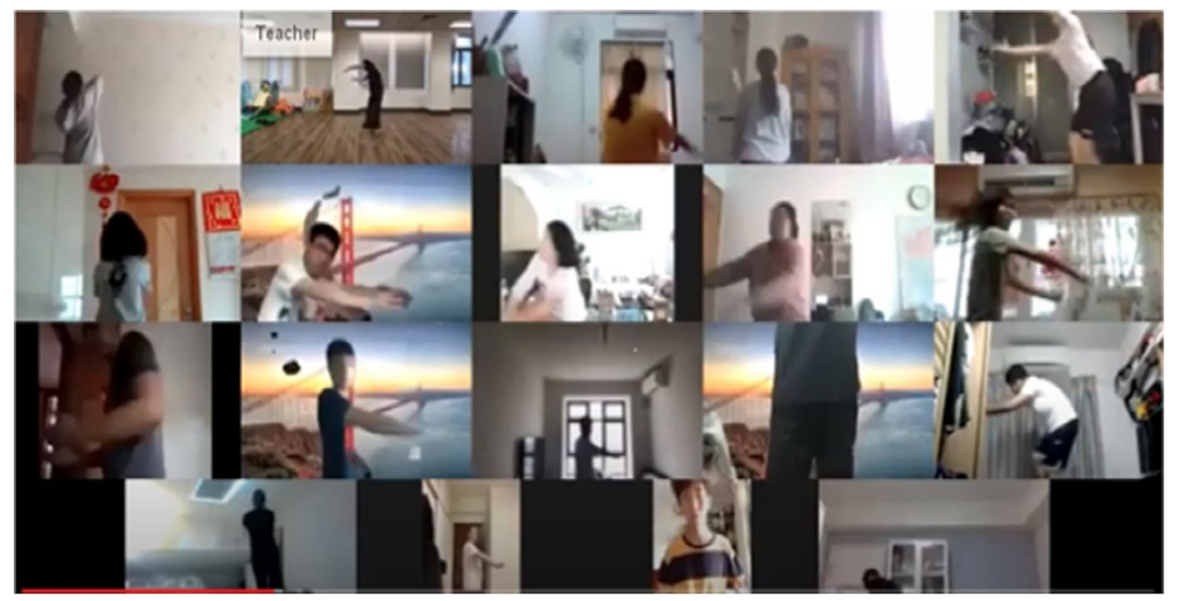

Fig. 3 A joint dancing course with students from the University of Macau

sections are explored, such as online discussion, team-based learning, online groupbased performance projects, which further strengthen students' professional practices in interactive learning. The framework of multi-component blended learning is illustrated in Fig. 1. As the 'E-learning mode' part is also used before the COVID19 Pandemic, following chapters mainly describe the 'Synchronous online teaching mode' (in the red colour).

\subsection{Online synchronous lecture}

Before the lecture, dance professors upload preproduction video to the Learning Management System (i.e., CANVAS in HKAPA), for students to retrieve/practice the learning materials before the synchronous training. During the lecture, teachers lead video conference with students via ZOOM, or other video live streaming technologies. Students are required to dress proper dancewear and take class during the synchronous dance class. Figure 2 shows a dance professor (studio) and students (home) in a synchronous dance class at HKAPA.

Figure 3 is a screen capture of a joint synchronous dance class with students from the University of Macau. Students are engaged in dance rehearsals with others, including the teacher in the synchronous online class. All participants in the class are from various countries, including South Korea, Hong Kong, mainland China, and Macau.

These synchronous classes are positively commented by the teachers with the following characteristics: 


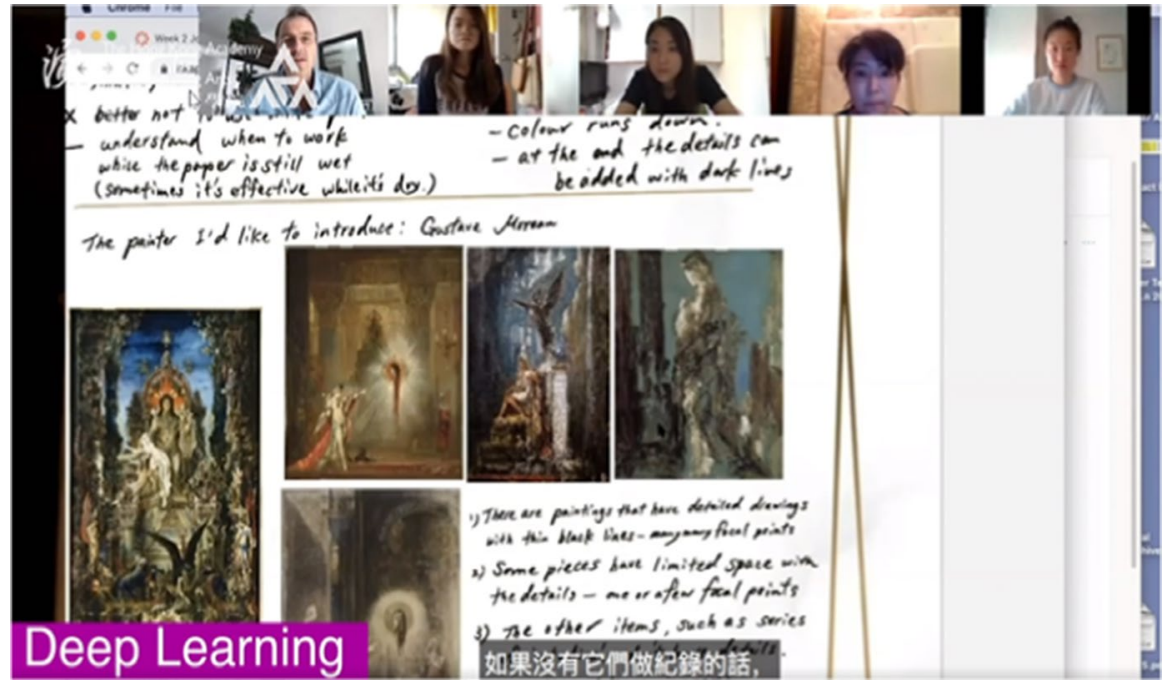

Fig. 4 A Scenic Art course for Technical and Entertainment Arts students

\subsubsection{In-depth learning}

The lecture video are recorded for students to review/ practise before and after class. A professor at the School of Theatre and Entrainment Arts comments on the experience: 'I record every session, that actually turns out to be really useful. If it was not there, I think the students will struggle to remember everything.' (Fig. 4).

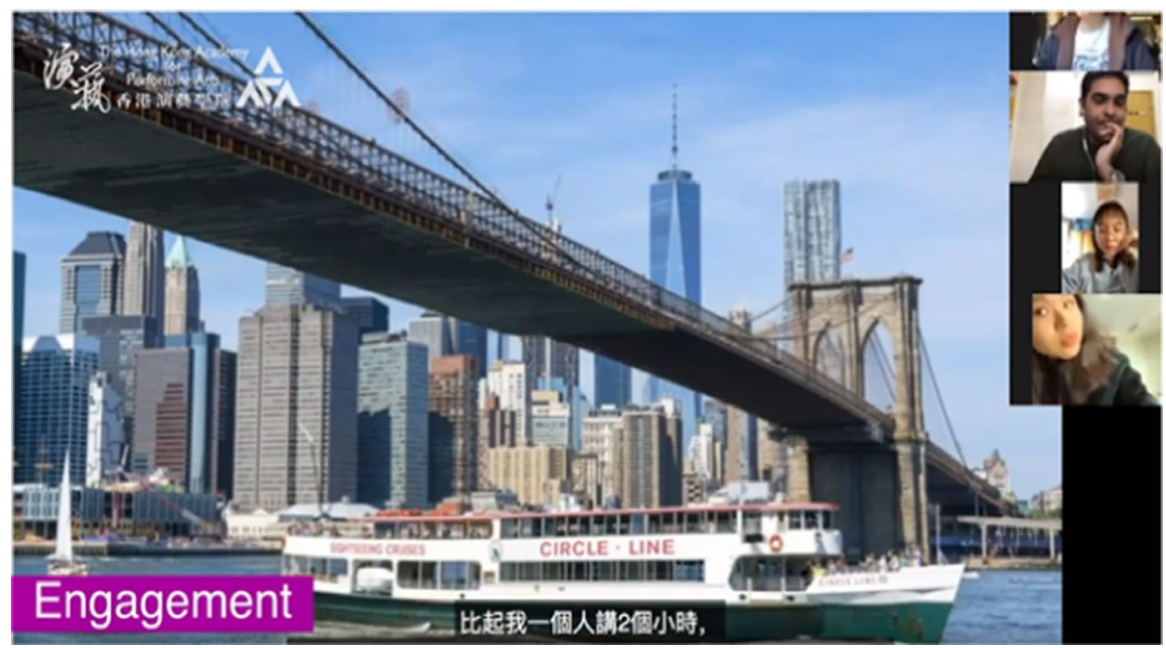

Fig. 5 A film production course for the Film \& TV students 


\subsubsection{Engagement}

The students are engaged in various online activities and that lead to active learning. In such case, students are put in small working groups (e.g., breakout rooms in Zoom) and each one is obligated to comment and reflect. A professor at the School of Film and Television shares his experience: 'I really like the functionality that it provides the breakout room. I was able to then go into each room and monitor them and see how they are doing. It can really help engage students so that it doesn't feel like. you are giving a lecture for $2 \mathrm{~h}$ straight'. (Fig. 5).

\subsubsection{Interaction}

Teachers and students can interact during the online classes, i.e. highlight the key points on the notes and share personal views on the same subject. An enthusiastic response session is shared by a professor at the School of Music: 'With the shared screen, we can look at the score together, I can also indicate to students where they should focus on'. (Fig. 6).

\subsection{Webinar}

The COVID-19 pandemic has changed performing arts teaching and learning, and art forms themselves. It has presented Academies with new opportunities to reconsider how classes should be conducted and what content material should be taught through efficient yet engaging ways. The pandemic has transformed performing arts by forcing artists and arts companies to innovate in the production, presentation and promotion of their art works. Inevitably, the pandemic has pushed students to think beyond graduation, about which paths they might take long before they get into their

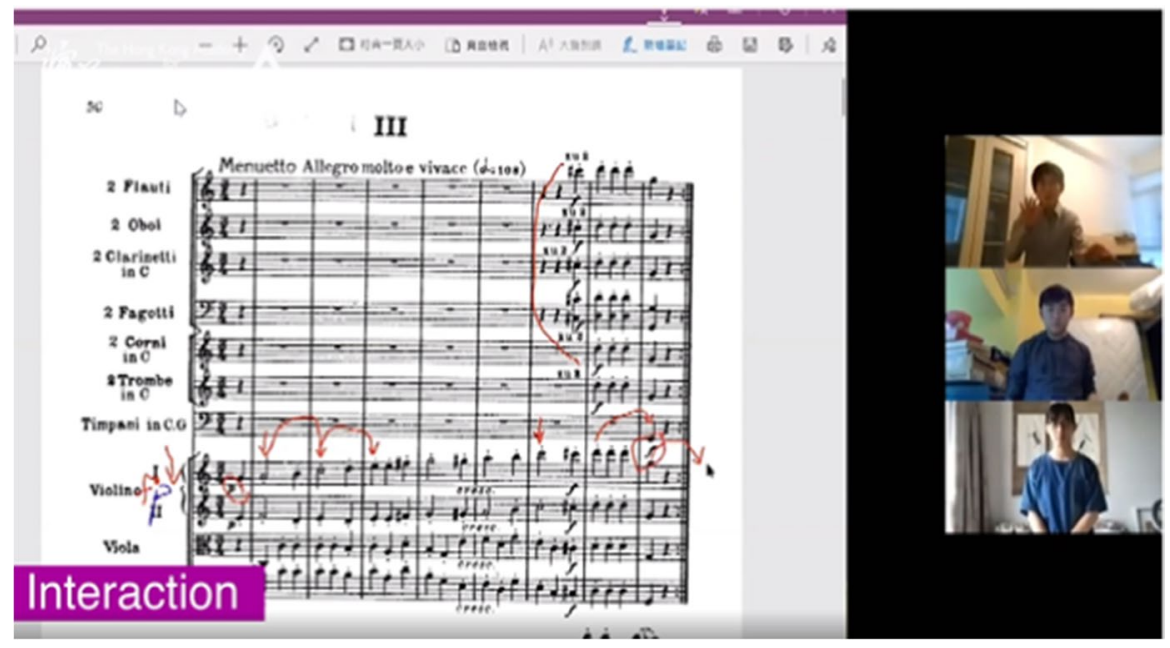

Fig. 6 Conducting class for Music students 
professional careers. These changes pose challenges as well as create opportunities for all performing arts educators and students.

With that in mind, HKAPA has organised a series of webinars for internationally renowned artists to exchange ideas. The monthly webinars 'Future of Performing Arts education' is one of the very few events in the world addressing such specific needs in performing arts during the pandemic. Well established performing arts educators are invited as guest speakers, i.e. Professor Gillian Choa (Director, HKAPA), Professor Curtis Bonk (Professor at the School of Education, Indiana University) Professor Sarah Ellis (Director of Digital Development, Royal Shakespeare Company), Professor Sharon Choa (Dean of the School of Music, HKAPA) and Professor Michael Anderson (Professor in Education, Arts and Creativity, the University of Sydney). Speakers share their views and experience of making performing arts education work online. The webinar series provides a chance for speakers to take stock as practitioners compelled by the pandemic to teach away from studios, labs and classrooms and to keep classes running on desktops, laptops and mobile devices. This series provides a forum for colleagues from a range of performing arts and creative disciplines to share glimpses of the future of education - how and what we have done and ways to implementing them into the future. (see. Fig. 7)

One of the webinars focuses on how to make the performing arts work online. Two broad approaches to online crisis teaching emerged. For the speaker, Professor Michael Anderson, 'the pandemic has given a head of steam to what he terms technological determinism, in which the pressure to technologies drives learning'. He urges teachers to think of learning first and the technology second. In his view, understanding how students are motivated to learn, applying tried and tested frameworks that structure creative learning processes and employing the best variety of pedagogical practices should govern our approach to 'live' and online teaching equally. Another speaker asserts that the disruption caused by the COVID-19 pandemic is an opportunity for performing arts educators to transform their practice in ways borne out by research, and for institutions to review their curricula in terms of how the class should be taught, when, and through what medium - 'doing the things online that make sense online.'

Over the course of the webinar series, participants have brought a wide range of ideas and practical examples to light. It is one of the rare opportunities to share such practical approach to teaching performing arts courses remotely without time to prepare
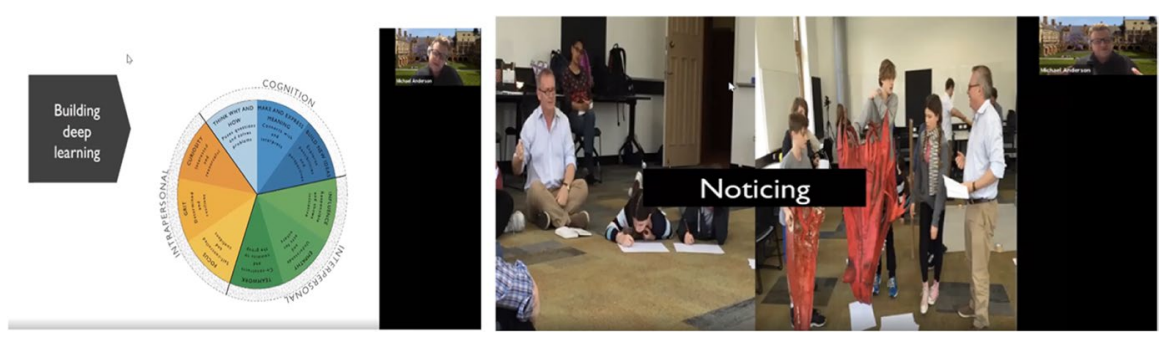

Fig. 7 Future of Performing Arts education Webinar - (Professor Michael Anderson, University of Sydney) 
and test-out, or prior experience to draw upon. In that sense, it is fit-for-purpose and a team-based brainstorm event. Webinars also encourage performing arts educators to experiment, innovate, and reflect on what works and what does not, gaining experiences as they go along. By seeing creativity as the only way to mitigate the crisis, and by viewing teaching as a creative act, delivering a course online is as learning-rich for the teacher as it is for the students. Looking forward, this approach should involve the students in co-creating process in the future. Present students are digital natives, and the online world is their natural habitat. They know what they want, where resources are, and how to access them efficiently. All guest speakers agree that this approach encourages resourcefulness in students and provides an opportunity to 'to step up and shine.' This increased responsibility is a beneficial counterbalance to teachers' common inclination to underestimate their students. Finally, by involving students, teachers step off the stage and becomes a facilitator providing guidance in online classes. They serve multiple roles in such a learning community. They not only lead but to create, develop, guide, and facilitate learning process instead of disseminating just the knowledge.

\subsection{Innovative performance projects}

This project is designed to encourage students to create innovative artwork (s) or project (s), with higher-order thinking and to promote themselves in the arts-self-efficacy, inspired by the artistic restrictions caused by the COVID-19 pandemic. It fosters collaboration, creativity, critical thinking, and communication skills (4C skills) among performing arts students. It motivates students to articulate, think outside of the box and generate original ideas in various group presentations and projects.

Ten projects are submitted, including site-specific solo dance, group of cello players, and a combination of art forms with students from various schools at HKAPA. The last one forms an interdisciplinary approach to performing arts creation. These projects demonstrate advanced skills, techniques, innovative use of technology; the creative

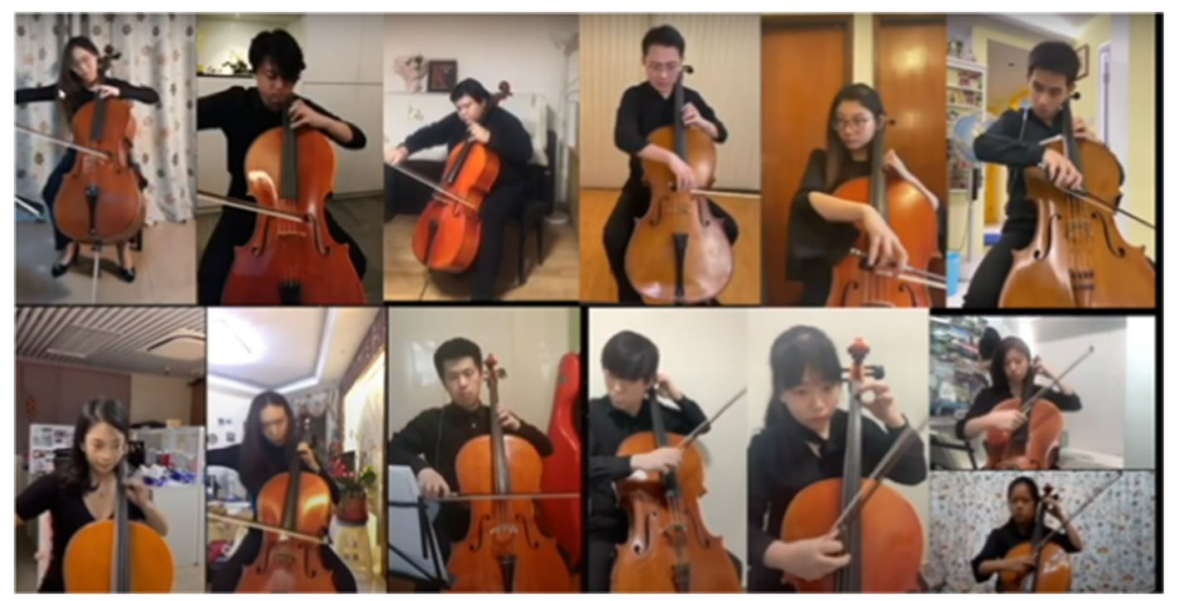

Fig. 8 Ritual Fire Dance 


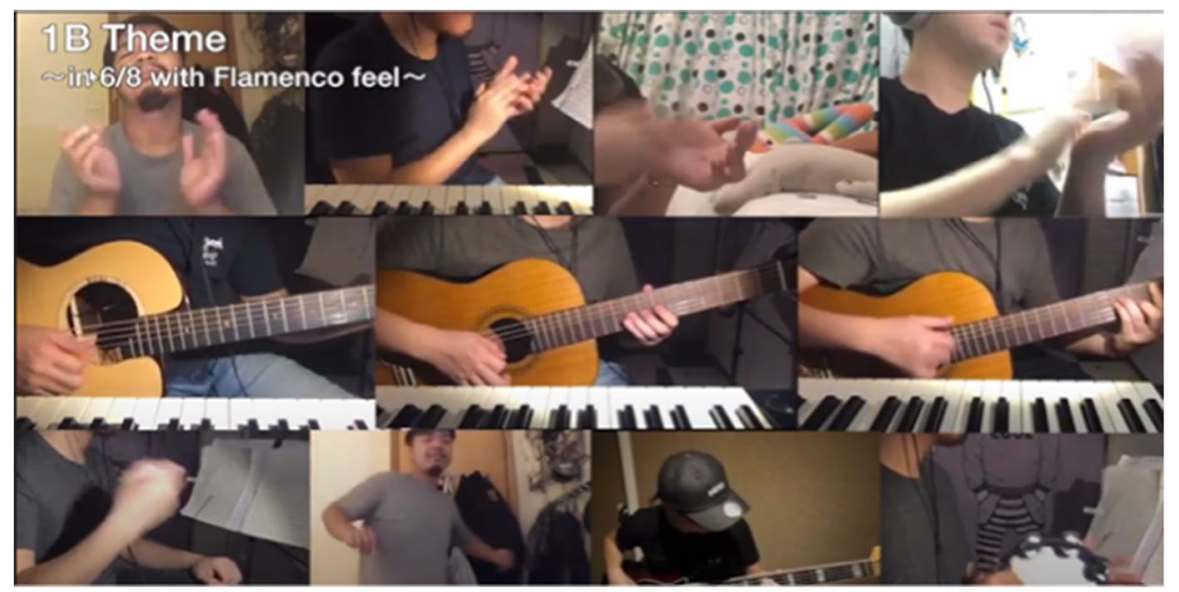

Fig. 9 Hotel California

and original idea from students; and inspired by restrictions caused by the COVID-19 pandemic.

Figure 8 shows a group cello performance-Ritual Fire Dance. The musicians (from various parts of the world) hope to use the song, Ritual Fire Dance (Manuel de Falla) to lessen the misfortune feelings caused by the pandemic, with the hope that it will end soon, and normality will return.

Figure 9 demonstrates the creative collaboration and original work from the students at the School of Theatre and Entertainment Arts, who often referred as people lacking creativity and only focus on technical speciality. With a background music, they want to showcase their peers and their creativity to produce a message beyond music during the COVID-19 pandemic. In a short time, a group of students came up with a unique revised work of Hotel California by the Eagles, showing that although the social isolation separated them from one another, they were connected by music and creative minds.

Table 1 The survey respondents

\begin{tabular}{llllll}
\hline & \multicolumn{2}{l}{ Teacher } & & \multicolumn{2}{l}{ Student } \\
\cline { 5 - 6 } \cline { 5 - 5 } School & No & $\%$ & & No & $\%$ \\
\hline School of Chinese Opera & 8 & $10.50 \%$ & & 11 & $6.80 \%$ \\
School of Dance & 11 & $14.50 \%$ & & 48 & $29.60 \%$ \\
School of Drama & 10 & $13.20 \%$ & & 9 & $5.60 \%$ \\
School of Film and Television & 2 & $2.60 \%$ & & 10 & $6.20 \%$ \\
School of Music & 4 & $5.30 \%$ & & 31 & $19.10 \%$ \\
School of Theatre \& Entertainment Arts & 21 & $27.60 \%$ & & 52 & $32.10 \%$ \\
Complimentary Studies & 9 & $11.80 \%$ & & NA & NA \\
Other & 11 & $14.50 \%$ & 1 & $0.60 \%$ \\
Total: & 76 & $100 \%$ & 162 & $100 \%$ \\
\hline
\end{tabular}




\section{Result and discussion}

To know how has being the new pedagogy helped teachers' teaching and students' learning, during the temporary closure of the Academy, a short survey was sent to all teachers and students in July 2020. A total 76 teachers (out of 142 teachers) and 162 students (out of 741 Undergraduate \& Master's Degree students) from different schools and departments in the Academy participated in the survey (Table 1). Appendix 1 and 2 demonstrate the questionnaires for teacher and student. The aspects: Technology, Learning Environment, e-learning Pedagogy are the core issues in the hybrid pedagogy implementation, and highlighted by teachers and students from the survey. The survey result shows that the new pedagogy effectively surmounts the challenges caused by the COVID-19 pandemic. It also presents areas for further improvement.

\subsection{Technology}

With the rapid development of information and communication technologies (ICT), the use of various digital devices plays critical roles in Blended Learning. For both teachers and students, digital devices, internet access, asynchronous learning platforms (Canvas) are the most concerned factors.

Digital devices: Over half of the respondents (59\% of the teachers and $52 \%$ of the students) believe that students' lack of access to suitable digital devices negatively

Table 2 Teachers' and students' perspectives on the lack of access to Devices

\begin{tabular}{llrlrr}
\hline Teachers & No & \multicolumn{1}{l}{$\%$} & Student & No & $\%$ \\
\hline Strongly Disagree & 3 & $3.90 \%$ & Strongly Disagree & 18 & $11.10 \%$ \\
Disagree & 18 & $23.70 \%$ & Disagree & 48 & $29.60 \%$ \\
Agree & 22 & $28.90 \%$ & Agree & 42 & $25.90 \%$ \\
Strongly Agree & 23 & $30.30 \%$ & Strongly Agree & 42 & $25.90 \%$ \\
N/A & 10 & $13.20 \%$ & N/A & 12 & $7.50 \%$ \\
Total & 76 & $100.00 \%$ & Total & 162 & $100.00 \%$ \\
\hline
\end{tabular}

Table 3 Teachers' and students' perspectives on the lack of Internet access

\begin{tabular}{llllll}
\hline Teachers & No & $\%$ & Student & No & $\%$ \\
\hline Strongly Disagree & 3 & $3.90 \%$ & Strongly Disagree & 20 & $12.30 \%$ \\
Disagree & 9 & $11.80 \%$ & Disagree & 49 & $30.20 \%$ \\
Agree & 25 & $32.90 \%$ & Agree & 51 & $31.50 \%$ \\
Strongly Agree & 31 & $40.80 \%$ & Strongly Agree & 32 & $19.80 \%$ \\
N/A & 8 & $10.60 \%$ & N/A & 10 & $6.20 \%$ \\
Total & 76 & $100 \%$ & Total & 162 & $100 \%$ \\
\hline
\end{tabular}


Table 4 Respondents have used Canvas

\begin{tabular}{lllllr}
\hline & \multicolumn{2}{l}{ Teacher } & & \multicolumn{2}{l}{ Student } \\
\cline { 5 - 6 } \cline { 5 - 5 } Schools & No & $\%$ & & No & $\%$ \\
\hline School of Chinese Opera & 6 & $17.60 \%$ & & 10 & $12.00 \%$ \\
School of Dance & 9 & $26.50 \%$ & & 24 & $28.90 \%$ \\
School of Drama & 0 & $0.00 \%$ & & 2 & $2.40 \%$ \\
School of Film and Television & 2 & $5.90 \%$ & & 6 & $7.20 \%$ \\
School of Music & 3 & $8.80 \%$ & & 17 & $20.50 \%$ \\
School of Theatre \& Entertainment Arts & 4 & $11.80 \%$ & 23 & $27.70 \%$ \\
Complimentary Studies & 6 & $17.60 \%$ & & 0 & $0.00 \%$ \\
Others & 4 & $11.80 \%$ & 1 & $1.20 \%$ \\
Total & 34 & $100 \%$ & 83 & $100.00 \%$ \\
\hline
\end{tabular}

affected their learning. (Table 2). One student asserts: 'I couldn't see the teacher from the small screen of my mobile phone.'

Internet access: $74 \%$ of the teachers and $51 \%$ of the students reported that there has to be a better bandwidth/Wi-Fi accessibility to maintain effective synchronous online learning. (Table 3).

Teachers and students suggest the institution to provide financial assistance for the purchase of laptops; or negotiate with vendors to sell no-cost or heavily discounted equipment; extend financial aid to cover internet costs for students with financial needs (there is subsidy but expires soon). All suggestions are recommended to senior management at HKAPA to ensure teaching and learning quality.

Asynchronous learning management platform (LMS-Canvas): About half of the respondents ( $46 \%$ of the teachers and $51 \%$ of the students) have used Canvas during the pandemic. Many of these Canvas users (97\% of the teachers and $71 \%$ of the

Table 5 Respondents have used Zoom

\begin{tabular}{lllllr}
\hline & \multicolumn{2}{l}{ Teacher } & & \multicolumn{2}{l}{ Student } \\
\cline { 2 - 3 } \cline { 5 - 6 } & No & $\%$ & & No & $\%$ \\
\hline School of Chinese Opera & 6 & $8.80 \%$ & & 11 & $7.60 \%$ \\
School of Dance & 10 & $14.70 \%$ & & 43 & $29.70 \%$ \\
School of Drama & 10 & $14.70 \%$ & & 6 & $4.10 \%$ \\
School of Film and Television & 2 & $2.90 \%$ & & 10 & $6.90 \%$ \\
School of Music & 4 & $5.90 \%$ & & 29 & $20.00 \%$ \\
School of Theatre \& Entertainment Arts & 8 & $11.80 \%$ & & 46 & $31.70 \%$ \\
Complimentary Studies & 9 & $13.20 \%$ & & 0 & $0.00 \%$ \\
Others & 11 & $16.20 \%$ & & 0 & $0.00 \%$ \\
Total & 68 & $100.00 \%$ & 145 & $100.00 \%$ \\
\hline
\end{tabular}


students) report that this type of platform is useful in supporting learning and teaching in the 'hybrid learning' pedagogy. (Table 4).

About $90 \%$ of the respondents have used Zoom, with $86 \%$ of teachers and $63.7 \%$ of students reporting satisfaction with this type of conference tool. Some teachers have commented that paid Zoom licenses are very useful and efficient However, students raise some concerns about privacy and security regarding Zoom. (Table 5).

\subsection{Learning environment}

$76 \%$ of the teachers and $56 \%$ of the students have reported that home environment hindered their learning. Many students live in small or multi-generation apartment. Meanwhile, there are also students prefer online learning as it allows greater flexibility or even promotes personal growth (Table 6). This is particularly evident to asynchronous learning.

Due to Hong Kong's housing shortage, it is a real challenge for learningfrom-home environment. It is hard to learn dance online at home for students to get the same quality or feel of the dance than if they were in dance studios. The home floor is hard to do small jumps or pirouette (multiple turns) for dance students. One student of the School of Dance comments: 'it has helped me become a more resilient student and dancer. I have to focus more and become more aware of what the teacher/ mentor is explaining things. It has also challenged my inner-discipline to stay motivated and to continue pushing through my goals.'

To address these concerns, the academy sends out notification reminding teachers about space restrictions. Academic staff must carefully consider the realities of students' home environments and other factors when designing hybrid course delivery. That includes what can and cannot be taught online allow staff to adjust teaching accordingly. Staff are strongly recommended to consider what content should be delivered synchronously (or live) and asynchronously via learning management system (Canvas).

On the other hand, students appreciate the flexible practice time. Some student share similar comments such as this one: 'I personally enjoy online classes quite a lot. It is not a bad idea to have lessons at home where it allows flexibility.'

Table 6 Teachers \& Students' Perspectives on if their Home Environment Hindered Learning

\begin{tabular}{llllrr}
\hline Teacher & No & $\%$ & Student & No & $\%$ \\
\hline Strongly Disagree & 4 & $5.30 \%$ & Strongly Disagree & 20 & $12.30 \%$ \\
Disagree & 7 & $9.20 \%$ & Disagree & 37 & $22.80 \%$ \\
Agree & 27 & $35.50 \%$ & Agree & 32 & $19.80 \%$ \\
Strongly Agree & 31 & $40.80 \%$ & Strongly Agree & 59 & $36.40 \%$ \\
N/A & 7 & $9.20 \%$ & N/A & 14 & $8.60 \%$ \\
Total & 76 & $100 \%$ & Total & 162 & $99.90 \%$ \\
\hline
\end{tabular}


The loss of access to facilities on campus created barriers to learning. As a leading performing arts institution in the world, teaching at HKAPA is not only about knowledge dissemination, but also attaining artistic skills. Because of lacking the equipment and space, it is hard for students' practice, especially the FTV, Dance, and TEA students. They already pay close attention to teachers' demonstration but without touching and seeing the material in person, it is almost impossible to learn. Same dilemma are shared by teachers, too. One comment from a dance teacher: 'It was difficult for me to observe how well my students could take in the information and it's very challenging for practical subject like movement for the same reason.'

\subsection{E-learning pedagogy}

Academic staff and students conclude that interaction, class length, and online resources are main components for effective hybrid learning pedagogy. Here are some key findings.

Interaction: the development of active interactions with students is essential: 1) Teachers and students find that this is more difficult to be interactive online; 2) Students' reluctance to turn on their cameras is one obstacle; 3) Class size is another barrier for the effective interactions; 4) Students value smaller grouping for close observation.

Class length: from teachers, it's hard to know about students' attention span when they are learning online. Meanwhile, students require flexible schedule. Some teachers and students believe that the class size, duration and schedule need to be modified for effective online learning. One comment from a dance student: 'Teachers can alternate the length of their respective classes to one hour and thirty minutes and sometimes less. For Academic subjects, they can also alternate Zoom learning with uploading mp3's of their discussion on Canvas/ Academy email.' This would limit screen time and students can listen to recorded lectures on the bus or at home.

Online Resources: Teachers recognize the importance of creating learning resources for students to watch and read at their convenience. However, this takes a great deal of time to prepare, record, and revise before uploading for students. The additional workload of online teaching is raised by a number of academic staff. A lecturer of the School of Theatre \& Entertainment Arts comments, 'Online teaching is not simply lecturing on zoom. It takes time and effort to develop courses, materials and learning activities, the Academy can help by providing time to teachers to develop these and provide 'mechanical' assistance (video/audio editing, etc.), letting teachers focus on learning design.' 


\section{Discussion}

From the perspectives of both teachers and student, it is a big success of the new hybrid pedagogy, which is implemented in the performing arts education at HKAPA to surmount the challenges, caused by the COVID-19 Pandemic. It is not smooth as technology utilization in performing education is not widely practiced and researched. This study shows a great potential in the this field. In short, some key points from this study:

1. Financial assistance for the purchase of laptops or equipment, and negotiation with vendors to provide no-cost or heavily discounted equipment for faculties and students;

2. Wider and earlier adoption for the learning management system;

3. For course design, faculties should take students' home environments and other dilemmas into consideration;

4. To alleviate student frustration, faculties should use technology to enable synchronous and asynchronous teaching;

5. Appropriate training/ support/consultations should be in place for teachers to have a greater understanding of online and blended approaches.

\section{Conclusion and limitation}

To surmount the challenges caused by the COVID-19 pandemic, a hybrid pedagogy consists of mix teaching methods, including blended learning, flipped classroom, outcome-based, and student-centred learning is adopted at HKAPA. This model combines synchronous lectures (facilitated by technologies such as Zoom, Cisco Webex, Google Class, Panopto etc.) and asynchronous sessions (resource package on Canvas, learning management system). Webinar series and innovative performance projects further contextualise and consolidate this pedagogy among faculties and students. The teaching and learning survey shows evidence in the validity of using such a pedagogy. Moreover, the survey questionnaire does not contain the students' study year (year 1, year 2) and gender, which might reveal further data on how to improve hybrid pedagogy in terms of fulfilling different needs. This will be considered in a follow up study, investigating the effectiveness and efficiency of using digital learning at different levels in performing arts.

As the world morphs into an unfamiliar place after the COVID-19 pandemic, technology will play even bigger roles in education as well as in performing arts. As a leading performing arts institution in the world, HKAPA's forward-looking approach to innovative pedagogy could be applied in other performing arts conservatoires and academies. Albert Einstein said, 'in the midst of every crisis, lies great opportunity.' Although the COVID-19 pandemic has caused major 
challenges, this study shows that a good use of information technologies leads to rich and meaningful teaching and learning experiences.

\section{Appendix 1: The Survey Questionnaire for Teacher}

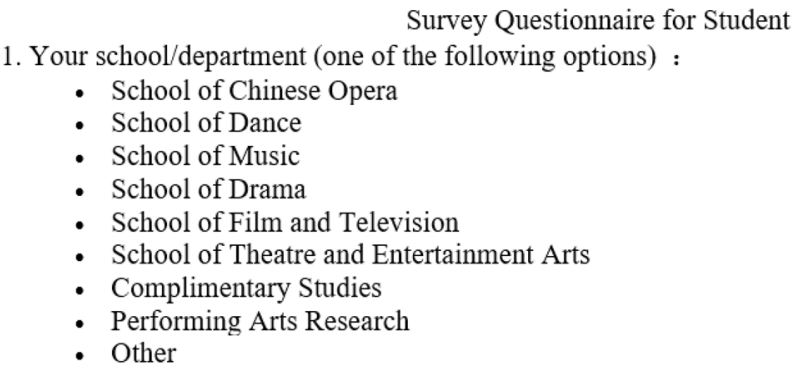

2. I learned online for my (Select all that apply) Via Zoom and similar live communication software (one of the following options)

- Theory-based courses

- Practice/performance-based courses

3. How did you learn during the Academy's closure due to Covid-19? (Select all that apply)

- Live lessons on Zoom or other platforms

- Access to online resources on Canvas

- Self-study/Practice

- I did not study during that time

- Other online platforms

4. To what degree do you agree with the following statements? During the Academy's closure:

Each question has the scale: (Strongly Agree $=4$, Agree $=3$, Disagree $=2$, Strongly Disagree $=1$, $\mathrm{N} / \mathrm{A}=0$ )

- Course resources on Canvas or other online platforms helped me learn

- My live lessons (on Zoom or other platforms) helped me learn

- I received good support from my teachers

- Working together with other students online helped me learn

- Online assessments helped me learn

- My WIFI access was too slow for online learning

- I needed better access to computers/mobile phones for online learning

- My home environment and physical space made it hard for me to learn

- I would like more training on how to learn online

- My teachers needed more training to teach effectively online

5. How has learning online affected you as a student in performing arts?

6. How can the Academy improve your online learning experience?

7. Any other comments?

8. Please enter your email if you don't mind. You may be contacted for a follow up interview. 


\title{
Appendix 2: The Survey Questionnaire for Student
}

\author{
Survey Questionnaire for Teacher
}

1. Your school/department (one of the following options) :

- School of Chinese Opera

- School of Dance

- School of Music

- School of Drama

- School of Film and Television

- School of Theatre and Entertainment Arts

- Complementary Studies

- Performing Arts Research

- Other

2. I taught online for my (one of the following options):

- Theory-based courses

- Practice/performance-based courses

3. How did you teach during the Academy's closure due to Covid-19? (Select all that apply):

- Via Zoom and similar live communication software

- Via Canvas

- I did not teach during that time

- Other online platforms

4. To what degree do you agree with the following statements? During the Academy's closure: Each question has the scale: (Strongly Agree $=4$, Agree $=3$, Disagree $=2$, Strongly Disagree $=1, \mathrm{~N} / \mathrm{A}=0$ )

- Course resources on Canvas or other online platforms helped me teaching

- My live lessons (on Zoom or other platforms) supported my teaching

- I was able to support students' learning

- Platforms I used enabled students to learn from each other

- Online assessments helped me support students

- WIFI access disrupted student learning

- Students' lack of access to computers/mobile phones disrupted their learning

- Students' home environment and physical space made it hard for them to learn

- I would like more training on how to teach online

- My students needed more training to learn online

5. How has learning online affected you as a teacher of performing arts?

6. How can the Academy better support you to teach online?

7. Any other comments

8. Please enter your email if you don't mind. You may be contacted for a follow up interview.

Data availability The datasets used and/or analyzed during the current study are available from the corresponding author on reasonable request. 


\section{References}

Amable, T. M. . (1983). The social psychology of creativity: A componential conceptualization. Journal of Personality and Social Psychology, 45, 357-376.

Anderson, J. D. (2012). Dance, Technology, and the Web Culture of Students. Journal of Dance Education, 12, 21-24.

Calvert, T., Wilke, W., Ryman, R., \& Fox, I. (2005). Applications of Computers to Dance. CG-M, 25, 6-12.

Cayari, C. (2011). The YouTube Effect: How YouTube Has Provided New Ways to Consume, Create, and Share Music. International Journal of Education \& the Arts, 12.

Colombi, E., \& Knosp, S. (2017). Teaching Dance with Online Course Management Systems. Journal of Dance Education, 17, 73-76.

Crawford, R. (2016). Rethinking teaching and learning pedagogy for education in the twenty-first century: Blended learning in music education. Music Education Research, 19, 1-19.

Draper P., \& Hitclock, M. (2008). The hidden music curriculum: Utilising blended learning to enable a participatory culture. International Society for Music Education World Conference.

Graham, C. (2004). Blended learning systems: Definition, current trends, and future directions. The handbook of blended learning: Global perspectives, local designs.

Kassab, M., Defranco, J., \& Laplante, P. (2019). A systematic literature review on Internet of things in education: Benefits and challenges. Journal of Computer Assisted Learning, 36, 115-127.

Leung, B. W., \& Leung, E. (2017). Teacher-Artist partnership in teaching Cantonese Opera in Hong Kong Schools: Student transformation.

Li, Z. (2020). Teaching Introduction to Dance Studies Online Under COVID-19 Restrictions. Dance Education in Practice, 6, 9-15.

Li, Z., Zhou, M., \& Teo, T. (2018). Mobile technology in dance education: A case study of three Canadian high school dance programs. Research in Dance Education, 19, 183-196.

Montgomery, A. P., Mousavi, A., Carbonaro, M., Hayward, D. V., \& Dunn, W. (2019). Using learning analytics to explore self-regulated learning in flipped blended learning music teacher education. British Journal of Educational Technology, 50, 114-127.

Ostashewski, N., Reid, D., \& Ostashewski, M. (2016). Utilizing Multimedia Database Access: Teaching Strategies Using the iPad in the Dance Classroom. Journal of Dance Education, 16, 122-128.

Peacock, S., Murray, S., Dean, J., Brown, D., Girdler, S., \& Mastrominico, B. (2012). Exploring Tutor and Student Experiences in Online Synchronous Learning Environments in the Performing Arts. Creative Education, 03, 1269-1280.

Power, J., \& Kannara, V. (2016). Best-Practice Model for Technology Enhanced Learning in the Creative Arts. Research in Learning Technology, 24, 30231-30316.

QS. (2021). QS World University Rankings [Online]. Quacquarelli Symonds. Available: https://www. topuniversities.com/universities/hong-kong-academy-performing-arts [Accessed].

Ruokonen, I., \& Ruismäki, H. (2016). E-Learning in Music: A Case Study of Learning Group Composing in a Blended Learning Environment. Procedia, Social and Behavioral Sciences, 217, 109-115.

Ruthmann, S. A., \& Hebert, D. G. (2012). Music Learning and New Media in Virtual and Online Environments. 1 ed.: Oxford University Press.

Zhou, M., \& Li, Z. (2019). Blended mobile learning in theatre arts classrooms in higher education. Innovations in Education and Teaching International, 56, 307-317.

Publisher's Note Springer Nature remains neutral with regard to jurisdictional claims in published maps and institutional affiliations. 


\section{Authors and Affiliations}

\section{Qingyun $\mathrm{Li}^{1} \cdot$ Zihao $\mathrm{Li}^{2}$ (1) $\cdot$ Jie $\mathrm{Han}^{3}$}

Qingyun Li

Qingyun.li@gmail.com

Jie Han

chan@ouhk.edu.hk

1 Xuzhou University of Technology, Xuzhou, China

2 The Hong Kong Academy for Performing Arts, Hong Kong SAR, China

3 The Open University of Hong Kong, Hong Kong SAR, China 